See discussions, stats, and author profiles for this publication at: https://www.researchgate.net/publication/304123880

\title{
Ethnic and socioeconomic inequalities in dental treatment at a school of dentistry
}

Article in The New Zealand dental journal · June 2016

CITATIONS

5

5 authors, including:

9. Jonathan M Broadbent

University of Otago

113 PUBLICATIONS 3,698 CITATIONS

SEE PROFILE

A. Lisa A Te Morenga

Victoria University of Wellington

78 PUBLICATIONS 1,826 CITATIONS

SEE PROFILE

Some of the authors of this publication are also working on these related projects:

Craniofacial Research View project

Project Trying to keep up with everything I have underway right now View project
READS

458

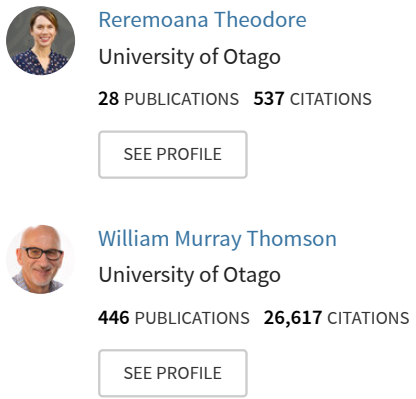




\title{
Ethnic and socioeconomic inequalities in dental treatment at a school of dentistry
}

\author{
Broadbent JM, Theodore RF, Te Morenga L, Thomson WM, Brunton PA
}

\begin{abstract}
Background and objectives: Health services should be targeted toward those most in need of health care. Poor oral health disproportionately affects Māori, Pacific Island, and socioeconomically deprived New Zealanders of all ages, and oral health care services should be prioritised to such groups. In New Zealand, free oral health care is available for all children up to the age of 17. On the other hand, adult dental services are provided on a user-pays basis, except for a limited range of basic services for some adults, access to which varies regionally. This study investigated the extent of dental treatment inequalities among patients at New Zealand's only School of Dentistry. Methods: Data were audited for all treatments provided at the University of Otago Faculty of Dentistry from 2006 to 2011 for patients born prior to 1990. Ethnic and socioeconomic inequalities in the provision of dental extractions, endodontic treatment, crowns, and preventive care were investigated. Differences were expressed as the odds of having received one or more treatments of that type during the six-year period 2006 to 2011. Results: Data were analysed for 23,799 individuals, of whom 11,945 (50.2\%) were female, 1285 (5.4\%) were Māori and 479 (2.0\%) were Pacific, 4040 (17.0\%) were of low socioeconomic status (SES), and 2,681 (11.3\%) were beneficiaries or unemployed. After controlling for SES, age, and sex, Māori had 1.8 times greater odds of having had a tooth extracted than NZ European patients, while Pacific Islanders had 2.1 times the odds. Furthermore, after controlling for ethnicity, age, and sex, low-SES patients had 2.4 times greater odds of having had a tooth extracted than high-SES patients, and beneficiaries had 2.9 times the odds. Conversely, these groups were less likely to have had a tooth treated with a crown or endodontics or receive preventive care. Conclusions: Existing policies call for the reduction of inequalities. There is a need for a strategy to monitor changes in treatment inequality over time which includes improving equity in service care provision. The observed treatment inequalities are likely to be an underestimate of those occurring in private dental practice in New Zealand.
\end{abstract}

\section{INTRODUCTION}

Lifelong oral health is a fundamental human right (World Health Organization, 2015). Poor oral health affects quality of life (Gerritsen et al., 2010) and the loss of tooth tissue can affect mastication, facial appearance, self-esteem and psychosocial well-being and future treatment options. Poor oral health disproportionately affects ethnic minorities and socioeconomically deprived New Zealanders across all ages. Māori (14.9\% of the New Zealand population) are similar to other indigenous populations in that they are substantially and consistently more likely to have poorer health than nonindigenous New Zealand peoples (Robson and Harris, 2007). New Zealand oral health and general health surveys conducted since the 1970s have reported that Māori children, adolescents and adults continue to have less access to dental care, and more untreated dental caries (decay) and tooth loss (Børsting et al., 2015; Cutress et al., 1979; Hunter et al., 1992; Ministry of Health, 2004; 2008; 2010). In the 2009 New Zealand National Oral Health Survey, proportionally more Māori (56\%) than NZ European (37\%) adults reported having been unable to access dental care in the past year due to cost (Ministry of Health, 2010). New Zealand Pacific Island children, adolescents and adults have also been reported to have poorer oral health and less access to dental services than non-Pacific populations, with adults having more teeth with untreated decay, and more teeth missing due to decay or periodontal disease (Børsting et al., 2015; Ministry of Health, 2010).

Dental health inequality research in New Zealand has focused on differences in the prevalence and severity of oral diseases and there has been less attention to investigating differences in the provision of dental care services that may be avoidable or unfair. Certainly, dental practices are not evenly distributed throughout New Zealand, and there are very few dental practices in areas with high proportions of Māori or Pacific people (Kruger et al., 2012). In an environment of user-pays dentistry, it is likely that ethnic and socioeconomic inequity in dental treatment occur because of the cost of care. Another issue that may also affect equity in the provision of dental care is the belief held by many, including some health professionals, that health problems are due to a lack of individual responsibility that is characteristic of certain population groups. However, recent research suggests that inequity in treatment provided for dental disease has a greater impact on dental health disparity than the experience of the disease itself (Mejia et al., 2014).

The Faculty of Dentistry at the University of Otago in Dunedin is New Zealand's only institution for the education and teaching of dentists. As a part of its programme, the Faculty of Dentistry clinics provide dental care at prices that are generally lower than those provided in private dental practice. The aim of this research was to describe ethnic and socioeconomic inequalities in the dental care provided through the Dunedin School of Dentistry dental clinics during the six-year period 2006 to 2011, and to consider their implications. 
Table 1. Characteristics of Faculty of Dentistry patients, 2006-2011

\begin{tabular}{|c|c|c|c|c|c|c|c|c|}
\hline \multirow[b]{2}{*}{ Ethnicity } & \multicolumn{2}{|c|}{$\begin{array}{l}\text { Birthdate } \\
<1960\end{array}$} & \multicolumn{2}{|c|}{$\begin{array}{l}\text { Birthdate } \\
\text { 1961-1980 }\end{array}$} & \multicolumn{2}{|c|}{$\begin{array}{l}\text { Birthdate } \\
\text { 1981-1990 }\end{array}$} & \multicolumn{2}{|c|}{ Overall } \\
\hline & & & & & & & & \\
\hline NZ European & 7640 & $(93.5)$ & 7040 & $(86.4)$ & 6204 & $(83.0)$ & 20884 & $(87.8)$ \\
\hline Māori & 269 & $(3.3)$ & 615 & $(7.6)$ & 401 & $(5.4)$ & 1285 & $(5.4)$ \\
\hline Pacific Islander & 97 & $(1.2)$ & 213 & $(2.6)$ & 169 & (2.3) & 479 & $(2.0)$ \\
\hline Asian & 168 & $(2.1)$ & 281 & $(3.5)$ & 702 & $(9.4)$ & 1151 & $(4.8)$ \\
\hline \multicolumn{9}{|l|}{ Socioeconomic category } \\
\hline High SES & 901 & $(11.0)$ & 1040 & $(12.8)$ & 251 & $(3.4)$ & 2192 & $(9.2)$ \\
\hline Medium SES & 2295 & $(28.1)$ & 2587 & $(31.8)$ & 1026 & (13.7) & 5908 & $(24.8)$ \\
\hline Low SES & 1360 & $(16.6)$ & 1836 & $(22.5)$ & 844 & (11.3) & 4040 & $(17.0)$ \\
\hline Student (includes $1^{\circ}, 2^{\circ}, 3^{\circ}$ ) & 227 & $(2.8)$ & 1259 & $(15.5)$ & 4840 & $(64.7)$ & 6326 & $(26.6)$ \\
\hline Retired & 2652 & $(32.4)$ & 0 & & 0 & & 2652 & $(11.1)$ \\
\hline Beneficiary or unemployed & 739 & $(9.0)$ & 1427 & $(17.5)$ & 515 & $(6.9)$ & 2681 & $(11.3)$ \\
\hline \multicolumn{9}{|l|}{ Sex } \\
\hline Female & 3888 & $(47.6)$ & 4001 & $(49.1)$ & 4056 & $(54.3)$ & 11945 & $(50.2)$ \\
\hline Male & 4286 & $(52.4)$ & 4148 & $(50.9)$ & 3420 & $(45.8)$ & 11854 & $(49.8)$ \\
\hline Total included & 8174 & $(52.1)$ & 8149 & $(57.7)$ & 7476 & $(61.1)$ & 23799 & $(56.6)$ \\
\hline Total excluded ${ }^{\mathrm{a}}$ & 7522 & $(47.9)$ & 5976 & $(42.3)$ & 4763 & $(38.9)$ & 18261 & $(43.4)$ \\
\hline Total & 15696 & & 14125 & & 12239 & & 42060 & \\
\hline
\end{tabular}

a Individuals with unknown sex, other/unknown ethnicity, unknown occupation were excluded

\section{METHODS}

Data on all treatment items recorded in the Faculty of Dentistry electronic database $\mathrm{e}^{1}$ between the years 2006 and 2011 were extracted and imported into the statistical analysis program Stata 13.1. Individuals born in 1991 or later were not included in the analyses, because this group included children who were likely to have received treatment under the Community Oral Health Service or Adolescent Oral Health Service. Data on ethnicity and/or occupation were missing for a number of individuals, and their data were excluded from the statistical analyses (Table 1). Treatments funded through the Accident Compensation Corporation, the adolescent oral health service or the community oral health service were not included in this analysis. The Faculty of Dentistry uses a separate fee schedule for holders of Community Service Cards (available to lowincome individuals in New Zealand); however, using these data, it was not possible to identify whether patients were holders of Community Service Cards at the time each service was provided. The Faculty of Dentistry also has different fee schedules for treatment provided by undergraduate students, postgraduate students, and staff members. For these analyses, data were available only on the code for each service item, not the fee schedule under which the treatment was invoiced.

Dental treatment items were coded using a modified version of the Australian Schedule of Dental Services (Australian Dental Association Inc., 2013). This uses three-digit codes for treatment items. Treatment items in the current analyses included dental extraction, endodontic obturation, placement of crown, and provision of a preventive service. Extraction categories included simple extractions (311), additional extractions ${ }^{2}$ (316), and surgical extractions (321) but excluded surgical extraction of

1 Titanium, Spark Dental

2 Where more than one tooth was extracted in the same treatment session lower third molar teeth, because this procedure is commonly performed prophylactically in the absence of disease. Endodontic treatment services analysed include obturation of an endodontic canal (417) or additional canal (418), but we excluded all pulpectomy and endodontic dressing procedures (obturation is the completion stage of root canal therapy, while pulpectomy and dressing procedures are interim procedures). Crown treatment services included porcelain crowns (613), porcelainfused-to-gold crowns (615), porcelain-fused-to-metal (not gold) crowns (622), and cast gold full crowns (618). Preventive care services included topical fluoride varnish treatments (121), dietary advice (131), and oral hygiene instruction (141).

The socioeconomic status of each patient was measured on a six-point scale assessing patients' self-reported occupational status (Elley and Irving, 1976). The scale places each occupation into one of six categories ( $1=$ professional, $6=$ unskilled labourer) based upon the educational level and income associated with that occupation in data from the New Zealand Census. For the purposes of statistical analysis, these were categorised as high (codes 1 and 2), medium (codes 3 and 4) and low (codes 5 and 6). Self-reported ethnicity information was collected based on the question "what is your ethnicity?", with response options of 'New Zealand European', 'Māori', 'Pacific Islander', 'Asian', or 'Other'. When enrolling as patients at the Faculty of Dentistry, individuals were able to select multiple ethnic categories on the patient registration form, but only one was entered into the electronic system (personal communication, Faculty of Dentistry main office staff). This was entered as the first ethnic group on the list with which the patient identified, meaning that a patient who identified as both 'NZ European' and 'Māori' would most likely have been entered as 'NZ European'. It was thus not possible to use ethnic prioritisation, since only one ethnic category was known for each patient. Note that the Faculty of Dentistry data capture and electronic entry forms have been changed in order to capture ethnicity data which 
are more in line with accepted norms in this country; however, those data were not available for these analyses.

Consultation was undertaken with the Ngāi Tahu Research Consultation Committee prior to conducting the research, and ethical approval was granted by the University of Otago Human Research Ethics Committee (reference HD15/017). Information on the dental procedures undertaken was recorded in paper notes by practitioners. This information was subsequently coded and entered into the Faculty of Dentistry's electronic database ${ }^{1}$. Duplicate patient records were merged and data were anonymised and imported into STATA 13.1 for statistical analysis. Logistic regression models were used to examine the association between dental outcomes, ethnicity, occupation-based socioeconomic status, and either age class category or age as at 2009.

\section{RESULTS}

After merging the duplicate records, 42,060 patients born prior to 1990 were identified as having had a record entered in the Faculty of Dentistry database between 2006 and 2011 (Table 1). Of these, 18,261 were excluded from analyses due to missing data on ethnicity, sex, or occupation, or due to having 'other' ethnicity. The excluded patients were mostly non-regular Faculty of Dentistry patients and those who do not have complete patient records. Analyses were limited to the remaining 23,799 individuals, of whom 5.4\% were Māori, 2.0\% Pacific Islander, $4.8 \%$ Asian, and the remainder NZ European Approximately $50.2 \%$ were female. Patients represented a wide range of occupations, and were of a similar age, ethnic, and socioeconomic profile to the wider Dunedin population as observed in the 2006 New Zealand Census. For example, in 2006, the population of Dunedin was 6.4\% Māori, 2.0\% Pacific Islander, $5.3 \%$ Asian, $78.7 \% \mathrm{NZ}$ European, and the remainder of 'other' ethnicity - this is close to the distribution of ethnicity among patients at the Faculty of Dentistry.

A total of 8,683 patients ( $45.4 \%$ female) had received one or more dental extractions (Table 2). Males had 1.3 times the odds of females of having had a tooth extracted. No significant sex differences were observed among those born between 1981 and 1990, but males born prior to 1960 had 1.4 times the odds of having had a tooth extracted than females (Table 2). Just over half of the Māori and Pacific Island patients had had one or more teeth extracted. After controlling for SES, sex, and age, Māori and Pacific Island patients had (respectively) 1.8 and 2.1 times the odds (of NZ European patients) of having had one or more teeth extracted. These differences were noted for all age groups but were greatest for younger Māori and Pacific Island patients. Socioeconomic status was also associated with having had one or more teeth extracted, with beneficiaries and those of medium or low SES being most likely to be treated in this way. This difference was more apparent among the youngest patients: among those born between 1981 and 1990, beneficiaries had 5.0 times the odds (of those of high SES) of having had a tooth extracted, and those of low SES were 3.1 times more likely to have had an extraction.

A total of 2,196 patients $(50.3 \%$ female) had received endodontic treatment (Table 3). Māori were less likely to have received endodontic treatment $(\mathrm{OR}=0.8)$. A low number individuals had received endodontic treatment in some age and year groups. Beneficiaries, students, and retired individuals were less likely to have received endodontic treatment.
A total of 983 patients (61.3\% female) had received one or more crowns (Table 4), although this included only four Pacific Island patients $(0.8 \%$ of the total). Statistically significant differences were observed by ethnicity, SES, and sex. After controlling for confounders, Māori and Pacific Island patients had 0.6 and 0.2 times the odds (respectively) of having received one or more crowns than NZ European patients (Table 4). Retired patients had 0.2 times the odds (of those of high SES) of having had a tooth crowned. Males, beneficiaries, students, and those of low SES were also significantly less likely to have had a tooth crowned.

Preventive services were provided to 3,209 patients $(52.0 \%$ female), $13.5 \%$ of the total (Table 5). Māori and Pacific Island patients were significantly less likely to have received a preventive treatment than NZ Europeans, while Asian patients were slightly more likely to have done. Only 28 of 269 Māori (10.4\%) born prior to 1960 and only 8 of the 169 Pacific Islanders (4.7\%) born between 1981 and 1990 had received a preventive care service. On the other hand, Asian patients were significantly more likely than NZ European patients to have received preventive care, and this was particularly apparent among those born between 1981 and 1990. Retired people were less likely and students more likely (than those of high SES) to have received preventive services. Males were less likely than females to have received preventive care.

\section{DISCUSSION}

The study provides not only information on ethnic and socioeconomic inequalities in dental treatment provision (within a very large low-cost dental hospital) but also insights into how New Zealand dental students may treat patients once they have completed their training. Relative to NZ European and Asian patients, Māori and Pacific Island patients were (i) more likely to have one or more tooth extracted, (ii) less likely to have one or more endodontic canals obturated, (iii) less likely to have one or more teeth crowned, and (iv) less likely to receive one or more free or low-cost preventive dental health services. Similar patterns were observed for beneficiaries and others of low SES.

Since this study was an audit analysis of data from routinelycollected dental treatment records, there are some important limitations, chief of which was the necessity to exclude a large number of individuals with missing data. Another limitation is that this was not a population-based sample (although those included in the study are broadly similar to the wider Dunedin population in terms of age and sex), and so the generalisability of the findings is unclear. A further limitation was the method of collecting data on ethnicity: many individuals may be inclined to identify with more than one ethnic category (such as both NZ European and Māori), but these electronic data could not account for this. The proportion of Māori patients may thus have been underestimated, and some who identified as both NZ European and Māori are likely to have been misclassified as NZ European. Despite these important limitations, the study also has a number of strengths, chief of which is the unique nature of the data. This is the first report of treatment inequities at New Zealand's only school of dentistry; it is not possible to obtain similar information from elsewhere. Another strength is that the audit still included a large number of people (equivalent in size to one-fifth of the population of Dunedin) 

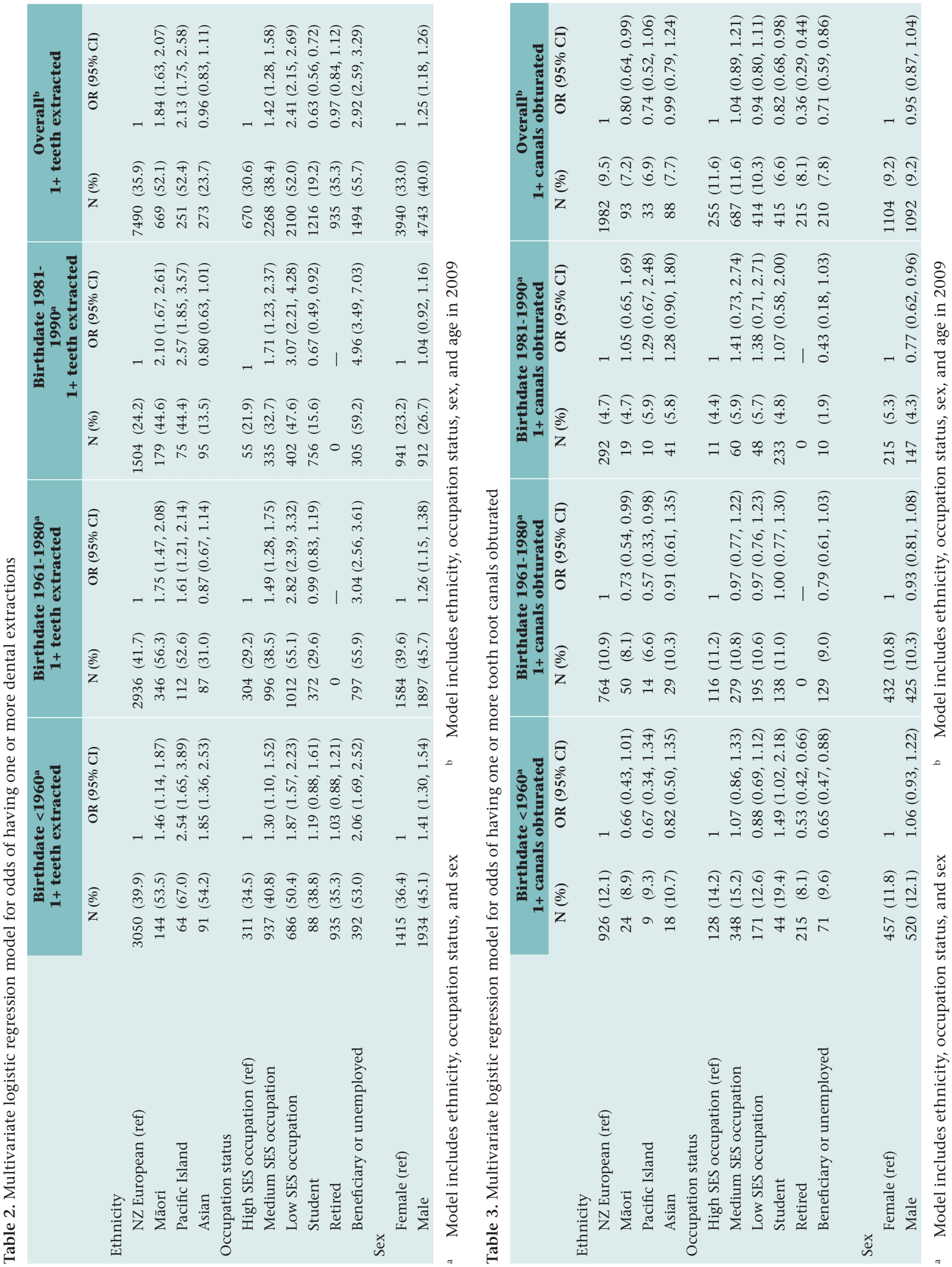

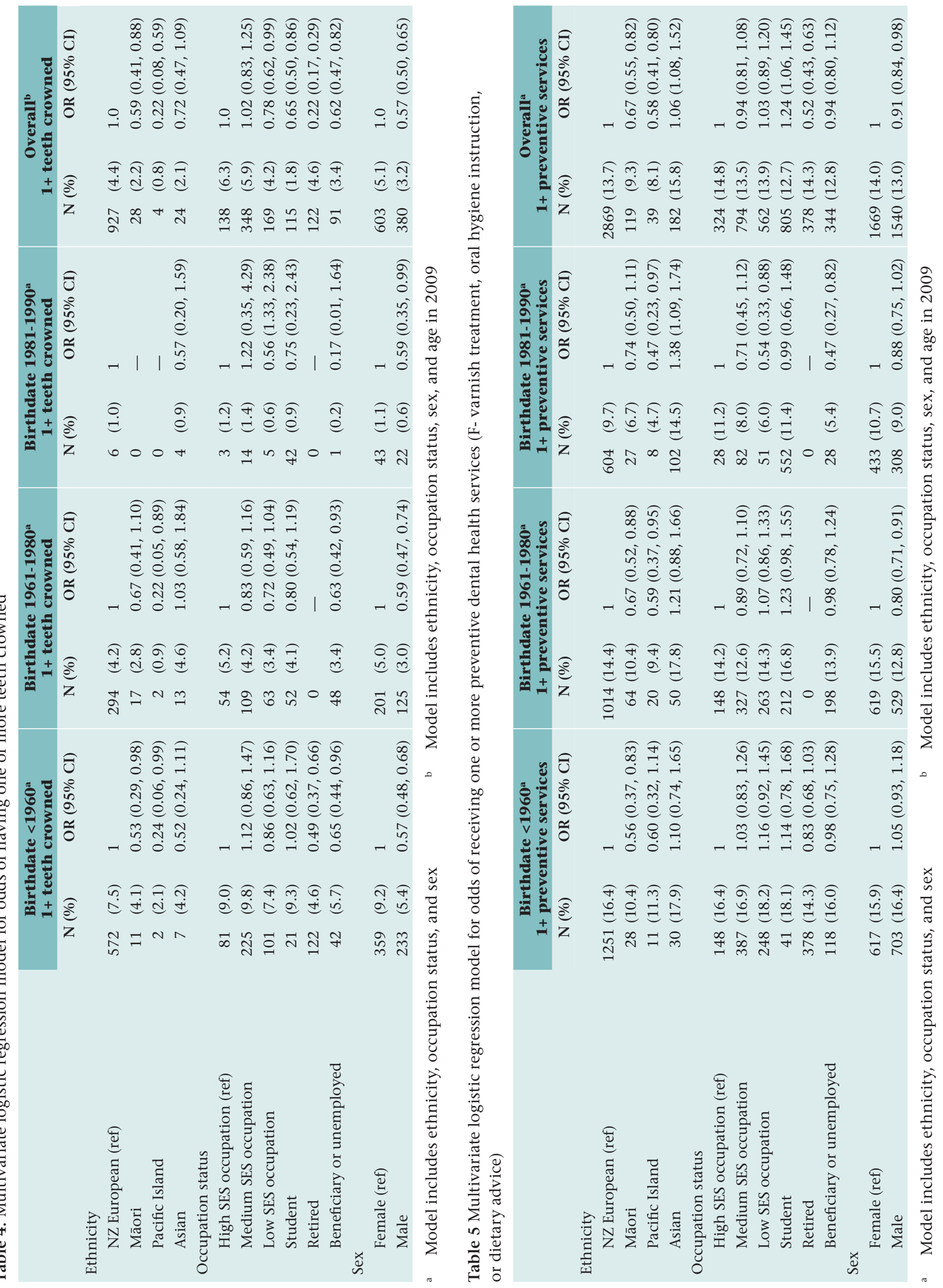
The Faculty of Dentistry clinics are available to everyone and provide relatively affordable dental services; however, statistically significant ethnic inequalities were observed even after controlling for SES, which suggests that SES alone does not explain the differences. Māori, Pasifika, and low income people did not receive equivalent care to other population groups, in that preventive care (which is free or low cost) and extraction alternatives were less likely to be received. These findings are similar to previous research that reported greater tooth loss and edentulism among 40-to-74-year-old Māori women than nonMāori, even when controlling for differences in education, age, and other health outcomes (Lawton et al., 2008). It is unclear whether extraction alternatives and preventive care (such as dietary advice, oral hygiene advice, or fluoride treatments) were offered to patients, since such information on whether patients refused this was not electronically recorded; all that we can show with these data is that it was less likely to be provided to Māori, Pacific, low SES people, and beneficiaries than other groups. A recent qualitative study found that, despite lowerincome Dunedin residents valuing good oral health and being knowledgeable about it, cost remains a primary barrier to their receiving appropriate care (Fitzgerald et al., 2015). Further research is needed to examine whether these patients are not being offered certain treatments or are less likely to accept the treatments when offered and to pinpoint why this may be occurring; nevertheless international evidence suggests that the treatment alternatives are commonly not offered in dental practice (Gilbert et al., 2003).

Interpersonal racism involves prejudice about the abilities, motives and intentions of others and discrimination resulting in differential actions towards others according to their race (Jones, 2000). Individuals who hold a negative stereotype about a group tend to automatically discriminate against a person who matches with that stereotype (van Ryn et al., 2011). In the dental setting, practitioners and students may make assumptions based on ethnicity or SES about whether a patient is likely to conform to a preventive care regimen. Alternatively, they might make judgements about a patient's ability to pay for alternatives to dental extraction. The effects of such interpersonal racism are illustrated by findings from the 2006/07 Health Survey (Ministry of Health, 2008), whereby Māori reported having experienced racial discrimination more frequently than NZ Europeans. Thus, interpersonal racism cannot be ruled out as an explanation for the treatment inequalities between Māori and Pacific people, and NZ Europeans observed in this study.

It might be argued that the differences observed in treatment are appropriate due to differences in severity of dental disease at the time of presentation. However, the argument is circular since the primary reason for low income New Zealanders to delay or avoid visiting the dentist is inability to afford routine dental care. More than half the participants in the 2006/2007 New Zealand health survey reported that the primary reason for being unable to see an oral health care worker was cost (Ministry of Health, 2008. Furthermore, late presentation for dental services does not explain the observed inequity in receipt of preventive services.

The Dental Council of New Zealand statement on best practice when providing care to Māori and Pacific island patients emphasises the importance of cultural competence in providing dental care (Dental Council of New Zealand, 2008). Very few dentists ( $<3 \%$ of the workforce) are of Māori or Pacific ethnicity, so increasing the numbers being trained is important, as well as ongoing training in-and maintenance of-cultural competence for all students and practitioners. This study focuses on overall service provision at the University of Otago Faculty of Dentistry. It is important to note, however, that, despite there being a small Māori dental workforce, a number of Māori oral health services do provide kaupapa Māori (for Māori by Māori) dental care in New Zealand (for a detailed description see-Broughton, 2006).

The treatment inequalities reported here are likely to underestimate those observed in private dental practice, where average fees for many common dental service items are as much as five times greater than those used at the Faculty of Dentistry. The New Zealand Dental Association (NZDA) position is that financial barriers to oral health care should be addressed through public funding (New Zealand Dental Association Low Income Project Working Group, 2014). On the other hand, the Standards Framework for Oral Health Practitioners (Dental Council of New Zealand, 2015) states that all oral health practitioners must treat patients fairly and without discrimination (ethical principle 4) and that practitioners must put the interests of patients ahead of financial gain (ethical principle 2). It is likely that there may be some debate about how these newly-implemented principles should be interpreted; however, it seems clear that all oral health practitioners are obliged to avoid inequities in treatment provision, regardless of a patient's financial means or the availability of public funding for their care.

The Faculty of Dentistry Strategic Direction 2013-2018 includes an aim of responsiveness to the needs of low socioeconomic status groups and Māori and Pacific peoples (Faculty of Dentistry, 2012) and indicates a number of action areas. These include (i) providing a learning environment that fosters awareness of the need to form collaborative working relationships with community partners, (ii) involving staff in policy development, and (iii) improved opportunities for community health including patient management to meet the needs of low socioeconomic status groups and Māori and Pacific peoples within the dental hospital and in outplacement clinics. Solutions to reduce inequity in dental care at the Faculty of Dentistry (as well as in wider dental practice) should involve ongoing consultation with Māori, Pacific and local community groups, and particularly Māori and Pacific Island care providers. There is need for transparency and a robust strategy of evaluation and monitoring of inequalities in treatment-including studies of this sort-to ensure that inequalities and resulting inequities are reducing as intended. This should include improvements in the collection of ethnicity information at the Faculty clinics (such as using the standard NZ Census ethnicity question) to better inform policy and practice. In addition, further research and good quality data are needed nationally to (i) inform the setting and monitoring of oral health targets, (ii) describe Māori value/belief frameworks about oral health, (iii) review the effectiveness of initiatives in improving Māori oral health including local initiatives and a national programme or framework for evaluation, (iv) strengthen public health research on oral health, and (iv) identify ways to integrate oral health into models of care for chronic disease (Robson et al., 2011; Stuart et al., 2011). 


\section{REFERENCES}

Australian Dental Association Inc. (2013). The Australian Schedule of Dental Services and Glossary. St Leonards: Australian Dental Association Inc.

Børsting T, Stanley J, Smith M (2015). Factors influencing the use of oral health services among adolescents in New Zealand. NZ Dent J 111:49-57.

Broughton J (2006). Oranga niho : a review of Māori oral health service provision utilising a kaupapa māori methodology: a thesis submitted for the degree of Doctor of Philosophy at the University of Otago, Dunedin, New Zealand.

Cutress T, Hunter PBV, Davis BP, Beck DJ, Croxson LJ (1979). Adult Oral Health and Attitudes to Dentistry in New Zealand 1976 Wellington: Medical Research Council of New Zealand.

Dental Council of New Zealand (2008). Council Statement: Best practices when providing care to Māori patients and their whānau. Wellington: Dental Council of New Zealand.

Dental Council of New Zealand (2015). Standards Framework for Oral Health Practitioners. Wellington: Dental Council of New Zealand.

Elley WB, Irving JC (1976). Revised socio-economic index for New Zealand. NZ J Educ Stud 11:25-36.

Faculty of Dentistry (2012). Strategic Directions 2013-2018. Dunedin: University of Otago.

Fitzgerald RP, Thomson WM, Huakau G, Darrou M, Gilmore D, Sadler H, et al. (2015). A qualitative study of the meaning of oral health and self-care for 40 Dunedin residents living on lower incomes. NZ Dent J 111:68-75.

Gerritsen AE, Allen PF, Witter DJ, Bronkhorst EM, Creugers NH (2010). Tooth loss and oral health-related quality of life: a systematic review and meta-analysis. Health Qual Life Outcomes $8: 126$.

Gilbert GH, Duncan RP, Shelton BJ (2003). Social Determinants of Tooth Loss. Health Services Res 38:1843-62.

Hunter PBV, Kirk R, de Liefde B (1992). The Study of Oral Health Outcomes: The New Zealand section of the WHO Second International Collaborative Study Wellington: Department of Health.

Jones CP (2000). Levels of racism: a theoretical framework and a gardener's tale. Am J Pub Health 90:1212-5.

Kruger E, Whyman R, Tennant M (2012). High-acuity GIS mapping of private practice dental services in New Zealand: does service match need? Int Dent J 62:95-9.

Lawton B, Rose S, Broadbent J, Keiser J, Sussex P, Thomson M, Dowell A (2008). Disparities in edentulism and tooth loss between Māori and non-Māori New Zealand women. Australia NZ J Pub Health 32: 254-60.

Mejia G, Jamieson DH, Spencer AJ (2014). Greater Inequalities in Dental Treatment than in Disease Experience. J Dent Res 93:966-71.

Ministry of Health (2004). A Portrait of Health: Key results of the 2002/03 New Zealand Health Survey. Wellington, NZ: Ministry of Health.
Ministry of Health (2008). A Portrait of Health: Key results of the 2006/07 New Zealand Health Survey Wellington: Ministry of Health.

Ministry of Health (2010). Our Oral Health: Key Findings of the 2009 New Zealand Oral Health Survey. Wellington: Ministry of Health.

New Zealand Dental Association Low Income Project Working Group (2014). NZDA Position Statement on Access to Oral Health Services for Low Income Adults. Auckland: New Zealand Dental Association.

Robson B, Harris R, editors (2007). Hauora: Māori Standards of Health IV: A study of the years 2000-2005. Wellington: Te Rōpū Rangahau Hauora A Eru Pōmare.

Robson B, Koopu P, Gilmour J, Rameka R, Stuart K, Simmonds S, et al. (2011). Oranga Waha - Oral Health Research Priorities for Māori: low-income adults, kaumātua, and Māori with disabilities, special needs and chronic health conditions. Wellington: Te Rōpū Rangahau Hauora a Eru Pōmare.

Stuart K, Gilmour J, Broadbent JM, Robson B (2011). Oranga waha - Oral health research priorities for Māori: literature review. . Wellington: Te Rōpū Rangahau Hauora a Eru Pōmare.

van Ryn M, Burgess DJ, Dovidio JF, Phelan SM, Saha S, Malat J, et al. (2011). The impact of racism on clinician cognition, behavior, and clinical decision making. Du Bois Review 8:199218.

World Health Organization (2015). Tokyo Declaration on Dental Care and Oral Health for Healthy Longevity,. World Congress 2015: Dental care and oral health for healthy longevity in an ageing society 13-15 March 2015, Tokyo, Japan: World Health Organisation. Available: http://www.who.int/ oral_health/tokyodeclaration032015/en/.

\section{ACKNOWLEDGEMENTS}

The authors gratefully acknowledge the assistance of Faculty of Dentistry administrative staff. The authors acknowledge the supporting work of Fatma Al Huraizi, Balquees Al Bahri, Eman Al Sayegh, and Jessica Henden. The authors report no conflicts of interest. Reremoana Theodore is supported by a Health Research Council Erihapeti Rehu-Murchie fellowship under grant number 13/579.

\section{AUTHORS}

Jonathan M. Broadbent ${ }^{1}$ BDS, PGDipComDent, PhD Reremoana F. Theodore ${ }^{2}$ BA, PGDipArts, PhD

Lisa Te Morenga ${ }^{2}$ BSc, BForSci, PhD

W. Murray Thomson ${ }^{1}$ BSc, BDS, MComDent, MA, PhD

Paul A. Brunton ${ }^{1}$ BChD, MSc, PhD, FDSRCSEd, FDSRCS, FFGDP(UK)

1 Sir John Walsh Research Institute, Faculty of Dentistry, University of Otago, Dunedin NZ

2 Department of Psychology, University of Otago, Dunedin NZ

3 Department of Human Nutrition, University of Otago, Dunedin NZ 